\title{
A Implantação da TV Digital sob a Perspectiva da Gestão do Conhecimento
}

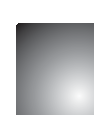

\author{
The Digital Television Implementation Under the Knowledge \\ Management Perspective
}

\begin{abstract}
Ariane Rodrigues Pereira
Mestre em Administração, Universidade Federal de Santa Catarina - Florianópolis - SC - Brasil. E-mail: arianerp@gmail.com

Marcos Baptista Lopez Dalmau

Professor e Chefe do Departamento de Ciências da Administração na Universidade Federal de Santa Catarina. Professor do Mestrado em Administração da UFSC. Florianópolis - SC - Brasil.E-mail: dalmau@cse.ufsc.br
\end{abstract}

Kelly Cristina Benetti Tonani Tosta

Professora Adjunta da Universidade Federal da Fronteira Sul - UFFS - Chapecó - SC - Brasil. E-mail: kellyadm@hotmail.com

Gilberto de Oliveira Moritz

Professor do Programa de Pós-graduação da Universidade Federal de Santa Catarina - Florianópolis - SC - Brasil.

E-mail: gomoritz@cse.ufsc.br

\section{Resumo}

Este estudo busca identificar a condução da implantação da TV Digital (TVDI) sob a perspectiva da gestão do conhecimento pela Televisão Lages Ltda. São feitas verificações sobre planejamento da TV Digital, metas de conhecimento e processos essenciais estabelecidos para propor sugestões de melhoria. A revisão teórica contempla Stewart (1998), Sveiby (1998), Davenport (2006), Angeloni (2002), Nonaka e Takeuchi (1997) e Terra (2002), com destaque a Probst, Raub e Romhardt (2002). Corroboram para o desenvolvimento do presente estudo as pesquisas do tipo aplicada, descritiva e explicativa, sendo a coleta de dados realizada através de entrevistas. O tratamento dos dados deu-se por meio de análise qualitativa. Destaca-se que o trabalho está limitado apenas ao SBT/SC, conta com as percepções do presidente, dos gestores e de uma publicitária da equipe para a implantação da TV Digital. A pesquisa está temporalmente compreendida entre agosto $e$ novembro de 2009 e limita-se ao escopo teórico adotado.

Palavras-chave: TV Digital. Implantação. Gestão do Conhecimento. Processos Essenciais.

\section{Abstract}

This study aimed at identifying the process of digital television implementation, under the knowledge management perspective, at Televisão Lages Ltda. It was performed analysis on the planning of digital TV, on the knowledge goals and on established essential processes, so that improvement suggestions could be given. The theoretical review is made up of Stewart (1998), Sveiby (1998), Davenport (2006), Angeloni (2002), Nonaka and Takeuchi (1997) as well as Terra (2002), nonetheless one must also highlight the views of Probst et al (2002). The study used the applied, descriptive and explanatory research in order to support its development, furthermore the data collection was performed by interviews. The data treatment was done by means of qualitative analysis. It is noteworthy that the work is limited only to SBT/SC; it relies on the perceptions of the president, managers and of an advertising professional. The research is temporarily limited by the months of August until November of 2009 and is restrained by the limitations of the adopted theoretical scope.

Key words: Digital TV; Knowledge Management; Essential process. 


\section{INTRODUÇÃo}

É possível testemunhar a revolução que a informação tem causado na sociedade, pois seus resultados podem ser vistos tanto na esfera social quanto na organizacional. Notadamente, essas mudanças são consequências do uso do conhecimento, o qual por sua vez adquire características de um recurso econômico proeminente, em alguns casos mais importante do que os insumos básicos; ocasionalmente, até mesmo mais importante do que o dinheiro. Conforme Smith e Kelly (1997, p. 219), "[...] na era agrícola, a terra era fundamental para estabelecer a vantagem estratégica e econômica". No entanto, com a transição para a Revolução Industrial deslocou-se o foco para aqueles que possuíam fonte de energia. Ao se ter em mente a transição para o futuro, o uso de tecnologia, de estratégia, de alianças globais e de inovação, se conjugados com o talento e o conhecimento humano, impulsionará a criação de uma vantagem competitiva para as organizações.

Observa-se, então, que, em meio a um ambiente competitivo e volátil, "[...] a capacidade das organizações, e não só das empresas, para sobreviver dependerá da sua 'vantagem comparativa' em tornar produtivo o trabalhador do conhecimento [...]”, conforme assertiva de Drucker (1999, p. 129). Para Sveiby (1998, p. 23), esses trabalhadores são profissionais altamente qualificados e com alto nível de escolaridade

[...] seu trabalho consiste, em grande parte, em converter informações em conhecimento, na maioria das vezes utilizando suas próprias competências, às vezes com o auxílio de fornecedores de informações ou de conhecimento especializado.

É válido ainda ressaltar que "[...] a revolução na tecnologia das comunicações trouxe mudanças econômicas que acentuam a importância do conhecimento [...]" (PROBST; RAUB; ROMHARDT, 2002, p. 12). Nesse sentido, observa-se que as vantagens da TV digital não se restringem apenas a fatores técnicos, como a otimização do espectro. Ela também propicia desenvolvimento no campo social e atende às demandas que surgiram com a Era do Conhecimento, o que antes não era possível com a TV analógica.
Nesse sentido, ao observar as atividades desse setor no âmbito catarinense, faz-se um destaque para a Televisão Lages Ltda. Dessa forma, o objetivo geral deste trabalho é analisar, durante o segundo semestre de 2009, como a filiada catarinense do SBT/SC tem conduzido a implantação da TV Digital (TVDI), sob a perspectiva da gestão do conhecimento. A seguir são destacados os objetivos específicos:

a) Verificar qual é o planejamento da empresa para a implantação da TV Digital;

b) Identificar a estrutura interna da empresa;

c) Constatar como a empresa gere o conhecimento;

d) Examinar, com foco na gestão do conhecimento, quais são os processos essenciais de conhecimento estabelecidos; $e$

e) Propor sugestões de melhorias.

\section{ReVISÃo TeÓRICA}

Com o advento da televisão digital, vive-se uma fase na qual há diversas possibilidades para a difusão e a elaboração de dados e de informações, que são as matérias-primas do conhecimento. Para Machado (2001), a verdadeira base da televisão é o discurso oral e a palavra.

A transição entre o modo de TV analógico para o modelo digital impulsiona diversas reflexões acerca das mudanças pelas quais o SBT/SC passará. Tais questionamentos são importantes, pois podem originar novas oportunidades de serviços e produtos de alto valor agregado.

Uma vez concluída a etapa de definição sobre o sistema e os padrões a serem adotados, as emissoras escolhem as tecnologias e iniciam os teste de transmissão, de recepção e de interoperabilidade. A fase que tem maior valor comercial é a referente à implantação em larga escala. De acordo com Montez e Becker (2005, p. 129), “[...] nessa fase começa a comercialização do sistema, ou seja, a transmissão em larga escala no sistema digital, juntamente com a transmissão analógica".

Tal transição no sistema de televisão é benéfica, porque demonstra a evolução que tem ocorrido no setor, visto de acordo com a assertiva de Montez e Becker (2005, p. 41), “[...] a TV analógica esgotou 
suas possibilidades de melhoramento tecnológico; não há como expandi-la ou melhorá-la para atender às demandas que surgiram com a Era do Conhecimento". Porquanto, verifica-se que dentre as vantagens advindas dessa mudança estão a qualidade e a otimização do espectro, além de principalmente a interatividade. Dessa forma, é possível estabelecer por meio da televisão digital uma comunicação entre o transmissor e o telespectador e, assim, promover serviços úteis e necessários à sociedade.

$\mathrm{O}$ acesso à internet é outro item de grande relevância, porque ao se adotar o modelo brasileiro de TV digital optou-se por um modelo que permite a inclusão digital. Notadamente, há um quadro de exclusão social no Brasil, o que acaba por adquirir uma conotação consequente de exclusão digital. Sendo assim, é uma tecnologia que não pode ser poupada, visto que [...] prover o acesso à internet pela TV não traz só novos telespectadores, mas também, ou melhor, novos internautas, atualmente excluídos do mundo virtual pela falta de acesso à tecnologia. (MONTEZ; BECKER, 2005, p. 42)

\subsection{Gestão do Conhecimento}

Ao se tratar do ambiente de conhecimento existente nas organizações, atualmente, é válido destacar que, para Probst, Raub e Romhardt (2002, p. 14), este "[...] é estruturalmente muito mais complexo do que aquele que existia há vários séculos". Tal fato ocorre visto que a taxa de crescimento do conhecimento experimentada tem se elevado consideravelmente. Além disso, pode ser explicado, também, em virtude da fragmentação do conhecimento e corroborado devido à ação da crescente globalização. Portanto, é importante conhecer como é composto esse ambiente organizacional, a fim de se transpor os obstáculos gerenciais referentes à gestão do conhecimento

Para Terra (2000, p. 70), "[...] a gestão do conhecimento está intrinsecamente ligada à capacidade das empresas em utilizarem e combinarem as várias fontes e tipos de conhecimento organizacional para desenvolverem competências específicas e capacidade inovadora”. É fundamental destacar que é possível, então, por meio da gestão do conhecimento, obter um desempenho diferenciado do mercado, representado por novos produtos, processos, sistemas gerenciais e liderança de mercado.

Por conseguinte, ao se adotar uma visão integrada, é possível assegurar que a base de conhecimento da empresa está sendo bem utilizada e possui um caráter contínuo. É válido destacar que, de acordo com o autor, "[...] a gestão do conhecimento não transformará a empresa; seu objetivo é simplesmente sensibilizar a administração em todos os níveis para a importância do conhecimento como um recurso".

Num contexto pragmático, entende-se que a gestão do conhecimento deve auxiliar os gestores a tratarem o conhecimento como um recurso, além disso, deve estimular ideias práticas que possam ser implementadas. Outras considerações, consoante a Nonaka e Takeuchi (1997), envolvem o conhecimento voltado à ação, além de abrangerem a necessidade de se fornecer uma matriz de análise com ferramentas comprovadas. É importante, também, a fim de se mensurar os resultados, desenvolver critérios para medir o sucesso; para tanto, faz-se necessário que a organização haja de forma compatível com os sistemas existentes e integre os métodos existentes para encontrar soluções. Por fim, é mister que seja formulada uma linguagem compreensível que possa ser usada nas atividades diárias da empresa.

Vale ainda destacar que, conforme Richter (apud ANGELONI, 2002, p. 39), "[...] a gestão do conhecimento despontou recentemente como uma nova sistemática de trabalho no ambiente organizacional". E, dessa forma, a gestão envolve características que estão relacionadas a determinadas crenças, pressupostos $e$ atividades que se baseiam em uma postura proativa, aberta, abrangente e atuante, presentes na cultura da empresa, que por fim possibilitam a gestão do conhecimento. É válido salientar que as organizações que se destacarão, conforme Drucker (2001), serão aquelas que souberem fazer uso da ciência cognitiva.

\section{A Produção nas Organizações do Conhecimento}

Além da qualidade da reação que as organizações demonstram em função das pressões competitivas, para Kelly (2001, p. 24), a empresa tem que se adaptar 
internamente para competir num cenário de constantes mudanças, ela também tem que refletir acerca da "imagem do futuro cliente e do futuro funcionário", pois para o autor haverá plena interação num modelo de empresa que agir como rede.

Dessa forma, torna-se tarefa econômica de grande valor, para indivíduos, empresas e países, organizar e gerir o conhecimento. Nesse sentido, Stewart (1998, p. 12) argumenta que o conhecimento "[...] tornou-se o principal ingrediente do que produzimos, fazemos, compramos e vendemos. Resultado: administrá-lo encontrar e estimular o capital intelectual, armazená-lo, vendê-lo e compartilhá-lo".

Para tanto, as Novas Tecnologias da Informação e da Comunicação Cordialmente (NTICs), exercem um papel importante no desafio organizacional. Elas são originadas a partir da reflexão de pessoas envolvidas num processo lógico, onde há, além de um envolvimento de capital humano, o uso de tecnologias, como microprocessadores, chips entre tantos outros que adquirem valor em função da interconexão existente.

\subsection{As Metas de Conhecimento}

Para que seja possível direcionar a gestão do conhecimento com o propósito de atender às expectativas de desenvolvimento de habilidades, Probst et al. (2002, p. 35-36) sugerem a utilização de metas do conhecimento, subdivididas em:

\begin{abstract}
Metas normativas - criar uma cultura empresarial ciente do conhecimento no qual as habilidades dos indivíduos são partilhadas $e$ desenvolvidas, tal posicionamento permite a organização realizar uma gestão eficaz do conhecimento;
\end{abstract}

Metas estratégicas - definem o conhecimento vital da organização e determinam as habilidades que serão necessárias no futuro; $e$

Metas operacionais - visam a implementação da gestão do conhecimento; fazem a tradução das metas normativas e estratégicas em objetivos concretos.

Salienta-se a importância e a relevância dessas metas para uma organização que visa exercer e vivenciar a gestão de conhecimento em todos os níveis organizacionais. Para tanto, as metas operacionais são essenciais, visto que elas buscam evitar que a gestão de conhecimento se esgote nos níveis de staff ou estratégico e também visam impedir uma situação em que o conhecimento seja sacrificado em função das operações da empresa.

Porquanto, uma das tarefas da administração é a definição de metas que oriente os processos essenciais da empresa. É necessário "[...] concordância sobre as metas estratégicas constituírem do elemento essencial do planejamento estratégico [...]", conforme afirma Probst, Raub e Romhardt (2002, p. 40), o benefício é o de promover uma direção geral às atividades da empresa, como, também, a influência que elas exercem sobre o comportamento dos funcionários.

As metas normativas de conhecimento referem-se à visão geral da política da empresa e a todos os aspectos de sua cultura empresarial. Já, as metas estratégicas de conhecimento são instituídas para programas de longo prazo que visam atingir a visão da empresa. Por fim, as metas operacionais de conhecimento oferecem suporte para assegurar o cumprimento dos programas estratégicos em suas atividades diárias. Assim sendo, as metas de conhecimento em todos os três níveis devem ser complementares entre si e devem ainda somar em conjunto para a realização das metas da empresa.

\subsection{Processos Essenciais de Gestão do Conhecimento}

Cada organização tem um conjunto específico de processos, os quais visam criar valor para os clientes $e$ produzir resultados financeiros. De acordo com Lobato et al. (2006, p. 116), "[...] é possível constatar que uma cadeia de valor genérica pode servir de modelo para que as organizações se adaptem ao construir a perspectiva dos processos internos". Nesse caso, inclui-se um processo de inovação, envolvido com a pesquisa de necessidades emergentes ou latentes dos clientes, o processo de operações que verifica desde a criação do valor até a entrega eficiente, regular e pontual dos produtos ou serviços e, por fim, o processo de serviço pós-venda ao cliente, que inclui a assistência após a aquisição do produto ou serviço.

Nessa visão, é possível para a empresa estruturar seus processos com foco em conhecimento, de forma a não apenas obter sucesso financeiro, mas também o crescimento dos ativos intangíveis. Para Probst, Raub e Romhardt (2002, p. 48), "[...] tratar o conhecimento 
como um recurso organizacional básico traz oportunidades significativas".

De acordo com Probst, Raub e Romhardt (2002), foram identificadas algumas atividades que podem ser consideradas processos essenciais da Gestão do Conhecimento (GC) e que, dessa forma, estão muito relacionadas. De forma resumida, a identificação do conhecimento significa analisar e descrever o ambiente de conhecimento da empresa. Conforme Probst, Raub e Romhardt (2002) atualmente há um grande número de empresas com dificuldades para definir um quadro geral de habilidades, o qual contenha informações e dados internos e externos. Isso, por sua vez, compromete a eficiência dos negócios e afeta a qualidade das decisões. Para Probst, Raub e Romhardt (2002, p. 33), "[...] a gestão eficaz do conhecimento deve, portanto, assegurar transparência interna e externa suficientes e ajudar os funcionários individuais a localizarem o que precisam".

Notadamente, as fontes de conhecimento de uma empresa não, necessariamente, são oriundas do ambiente interno. O seu relacionamento com clientes, fornecedores, concorrentes e parceiros contribui eficazmente para a aquisição do conhecimento, no entanto, segundo Probst, Raub e Romhardt (2002, p. 34), trata-se de "[...] um potencial que raramente é utilizado em sua totalidade". Nesses casos, a gestão sistemática do conhecimento deve passar por um processo de reflexão, o qual contempla algumas possibilidades como a de contratar o conhecimento de especialistas ou de adquirir outras empresas inovadoras, para que, dessa forma, obtenha o conhecimento necessário.

Nesse tocante, observa-se que o avanço continuado da ciência e da tecnologia tem ocasionado a rápida circulação de informações e a renovação do conhecimento. Logo, há constante obsolescência do conhecimento aplicado, e isso é traduzido como necessidade de atualização tanto para pessoas quanto para organizações. Para Rocha-Pinto et al. (2007, p. 108), "[...] trabalho e aprendizagem caminham juntos". Logo, outro procedimento importante, evidenciado como elemento construtivo, é o desenvolvimento

\section{do conhecimento.}

O foco desse processo está, conforme Probst, Raub e Romhardt (2002, p. 34), "[...] na geração de novas habilidades, novos produtos, idéias melhores e processos mais eficientes". Já, para Nonaka e Takeuchi
(1997), o desenvolvimento de novos produtos deriva dos processos de inovação. É válido, portanto, destacar que o esforço organizacional direcionado para o desenvolvimento do conhecimento é essencialmente administrativo e visa produzir capacidades que ainda não estão presentes na organização ou até mesmo que não existem fora dela.

Dando prosseguimento, Probst, Raub e Romhardt (2002, p. 34) ainda acrescentam que

[...] tradicionalmente, o desenvolvimento do conhecimento está ancorado em pesquisas de mercado da empresa e em seu departamento de Pesquisa \& Desenvolvimento, entretanto, um conhecimento importante pode também brotar de qualquer outra parte da organização.

Dessa forma, para Probst, Raub e Romhardt (2002), atividades entendidas como simples processos de produção podem ser observadas, otimizadas e convertidas em novas especializações, quando analisadas sob o ponto de vista da gestão do conhecimento.

Ao se refletir sobre como é possível levar o conhecimento ao lugar adequado, é necessário entender que para o compartilhamento e a distribuição de conhecimento organizacional são necessárias "[...] algumas condições prévias para transformar informações ou experiências isoladas em algo que toda a organização possa utilizar [...]", conforme Probst, Raub e Romhardt (2002, p. 34). Para tanto os autores propõem duas perguntas-chave, que são: Quem deve saber quanto sobre o que, ou ser capaz de fazer o que e em que nível? Como podemos facilitar o compartilhamento e a distribuição do conhecimento? Para Davenport (2006, p. 65), é importante "[...] gerenciar [...] as circunstâncias externas em que ocorre a distribuição do conhecimento".

Nesse processo, o pressuposto não é o de que todos saibam tudo numa organização. Pelo contrário, Probst, Raub e Romhardt $(2002,34)$ cita que "[...] o princípio da divisão de trabalho requer uma descrição e um gerenciamento significativo do escopo da distribuição do conhecimento". Nesse fluxo informacional, a etapa mais importante analisa a transição do conhecimento do indivíduo para o grupo ou à organização. $\mathrm{O}$ que vem ao encontro do posicionamento de Drucker (1999), quando ele diz que a empresa deve se organizar ao redor da informação, concentrar esforços, a fim de evitar que as pessoas fiquem confusas. 
Ao se evidenciar o conhecimento presente numa organização, possivelmente, surge um questionamento acerca de como é possível garantir que tal questionamento seja aplicado produtivamente em seu benefício. Nesse tocante, sobre a utilização do conhecimento, Probst, Raub e Romhardt (2002, 35) salientam que "[...] a identificação e a distribuição bem-sucedidas de conhecimento importante não garantem que ele será utilizado nas atividades diárias da empresa [...]", portanto, para os autores é mister que a organização se assegure para que habilidades e ativos de conhecimento valiosos sejam efetivamente utilizados.

Por fim, para completar o panorama acerca dos processos envolvidos na gestão do conhecimento, conta-se com a retenção do conhecimento. A qual está efetivamente ligada à função de gerir, isso porque "[...] a retenção seletiva de informações, de documentos e de experiências requer gestão [...]", conforme dito por Probst, Raub e Romhardt (2002, p. 35). Os autores ainda enfatizam que os processos, para selecionar, armazenar e atualizar, regularmente, um conhecimento de potencial valor futuro, devem ser estruturados cuidadosamente, para que não haja desperdício de uma competência técnica valiosa para a organização. Não obstante, ainda conforme os autores, a retenção do conhecimento depende da utilização eficiente de diversos meios de armazenagem disponíveis na organização.

É válido destacar que os processos essenciais de gestão do conhecimento produzem um cenário no qual é possível evidenciar quais são os problemas operacionais que podem decorrer ao se utilizar o conhecimento como recurso. Também deve ser observado que a gestão do conhecimento deve estar conectada à estratégica global da organização, a fim de garantir a eficiência dos processos. Nesse sentido, cabe à administração criar uma estrutura que coordene e dê as orientações para que sejam feitas intervenções operacionais quando necessárias. Para auxiliar nesse processo, Probst, Raub e Romhardt (2002, p. 35) acrescem dois elementos construtivos, a saber: objetivos do conhecimento e avaliação do conhecimento.

\subsection{Avaliação do Conhecimento}

Para completar o sistema proposto por Probst, Raub e Romhardt (2002), pode-se destacar a avaliação. Tal intento, não é novo ao se observar que sempre esteve presente tal fator enquanto fala-se sobre gestão. Conforme Davenport (2006, p. 45),

[...] na era industrial, essa era uma tarefa relativamente fácil; a produtividade de um trabalhador podia ser avaliada pelos resultados - o trabalho realmente produzido - ou pelas contribuições visíveis, que incluíam as horas trabalhadas ou o aparente esforço empreendido.

Entretanto, ainda conforme o autor, é muito mais difícil avaliar o desempenho, ou o conhecimento, em se tratando de trabalhador do conhecimento.

Nonaka e Takeuchi (1997, p. 268) também comungam desta ideia e ainda acrescentam que "[...] os membros da equipe devem ser avaliados na medida dos novos esforços tentados. Deve-se permitir que eles cometam "erros importantes". Para os autores, nas empresas que criam conhecimento, a mudança do critério de avaliação de um método negativo para um método positivo é uma necessidade.

Por fim, Probst, Raub e Romhardt (2002) abordam o processo de avaliação do conhecimento composto por duas fases. Primeiramente, para eles, as mudanças que ocorrem na base de conhecimento organizacional devem tornar-se visíveis, para que então sejam interpretadas frente às metas de conhecimento. Probst, Raub e Romhardt (2002, p. 195) faz ainda um destaque "[...] avaliar o conhecimento não significa calcular seu valor monetário; significa decidir se as metas de conhecimento foram ou não atingidas". Isso implica no segundo aspecto, que é referente à mensuração das mudanças que ocorrem no conhecimento para verificar onde isso ocorreu. Para os autores, isso acontece porque não há feedback para basear possíveis ajustes acerca dos vários elementos construtivos da gestão do conhecimento.

Dessa forma, verifica-se a importância desse elemento construtivo, a medição do conhecimento. Pois por meio desse conhecimento obtém-se um retorno, que demonstra se os objetivos de conhecimento estão formulados adequadamente e se as atividades de gestão do conhecimento são realizadas com sucesso. 


\section{Metodologia}

Para a caracterização da pesquisa atual, salienta-se que quanto aos fins, a pesquisa pode ser classificada, basicamente, como descritiva, visto que visa descrever as características da realidade organizacional quanto à gestão do conhecimento $e$ à implantação da TV Digital para a filiada catarinense do SBT-SC. Acresce-se ainda a classificação proposta por Ander-Egg (1978 apud OLIVEIRA NETTO, 2006, p. 24) quanto ao seu tipo: aplicada, uma vez que "[...] caracteriza-se por seu interesse prático, isto é, que os resultados sejam aplicados ou utilizados imediatamente na solução de problemas que ocorrem na realidade".

Quanto aos meios, a pesquisa é de campo, documental, bibliográfica e estudo de caso. Finalmente, considerada como estudo de caso, pois para Godoy (apud SILVA, 2003, p. 89), o estudo de caso "[...] caracteriza-se como um tipo de pesquisa cujo objeto de estudo é uma unidade que se analisa profundamente".

No que concerne ao método de pesquisa, optou-se por uma abordagem qualitativa baseada em métodos indutivos. Que objetiva, conforme Zanella (2006, p. 97), "[...] a descoberta, a identificação, a descrição detalhada e aprofundada[...]" do objeto de estudo, a fim de conhecer a realidade de acordo com a perspectiva dos sujeitos envolvidos na pesquisa.

Ressalta-se que, em função do método qualitativo, são evidenciados os sujeitos de pesquisa, ao invés de amostras, tal método para Zanella (2006, p. 107) "[...] não é empregado quando o pesquisador quer saber quantas pessoas têm preferência por um produto, portanto, não é projetado para coletar resultados quantificáveis". Logo, a escolha dos entrevistados deu-se em função da representatividade deles perante o tema. Contribuíram o presidente da organização, a publicitária que participa da equipe responsável pela implantação da TV Digital, o gestor de informática e novas tecnologias e o gestor técnico engenharia. Salienta-se não ter havido uma entrevista com o gestor de recursos humanos, visto que não há tal área na empresa estudada. Além disso, aplicou-se a todos os colaboradores, por meio do envio de um link, um questionário.

É importante destacar que para a execução do atual estudo há algumas limitações que devem ser apontadas: a) restringe-se apenas ao $\mathrm{SBT} / \mathrm{SC}$ e não incluem as demais organizações do grupo SCC; b) a amostra de pessoas entrevistadas limitou-se a quatro pessoas na organização; c) o estudo está delimitado entre agosto e novembro de 2009; e d) restringe-se ao escopo teórico.

\section{Análise dos Resultados da Pesquisa}

É possível compreender que qualquer organização pode tornar-se uma organização do conhecimento, contudo há um evidente destaque para empresas prestadoras de serviço e de tecnologia. A organização objeto do presente estudo é a filial catarinense do Sistema Brasileiro de Televisão, o SBT/SC, televisão Lages. O surgimento dela está intrinsecamente ligado ao desenvolvimento do Grupo Sistema Catarinense de Comunicação, o SCC. O grupo começou suas atividades com a vinda para Lages do técnico em manutenção de rádios receptores Carlos Joffre do Amaral de São Paulo, em 1939. Em fevereiro de 2008, a televisão Lages retomou uma anterior parceria com o SBT, momento em que a rede passou a se chamar SBT Santa Catarina.

\subsection{A Televisão Digital para o SBT/SC}

Atualmente, a organização tem trabalhado no sentido de preparar o dimensionamento do link entre Lages e Florianópolis, a fim de adequar o sistema de transmissão para a ocasião de sua instalação. Ainda no que tange à área técnica, outros preparativos quanto ao sistema de radiantes e torres estão sendo empreendidos.

Destaca-se que os principais atributos da TV Digital considerados pelo SBT referem-se à possibilidade de uso para o entretenimento, o comércio, a comunicação, a integração social e a educação. Entretanto, tais abordagens serão iniciadas pelo SBT nacional já que em relação à programação veiculada a maior parte de programas pertencem à rede. A emissora catarinense já esboça parcerias com universidades, a fim de viabilizar pesquisas e desenvolvimento de softwares que suportem a nova tecnologia digital.

Tendo em vista o cronograma oficial estipulado pela Agência Nacional de Telecomunicações (ANATEL), o qual especifica como prazo máximo final para 
a implantação e substituição da tecnologia analógica pela digital, o ano de 2016, as ações da empresa estão pautadas nesta delimitação. Todas as ações legais que envolvem o Ministério das Comunicações e a ANATEL estão sendo devidamente tratados pela equipe envolvida na implantação da TV Digital.

Por conseguinte, baseado no cronograma estabelecido pela ANATEL, o SBT/SC adotou a seguinte estratégia: com o foco no curto prazo, há o investimento para a melhoria e a expansão do sinal analógico, tendo em vista, a longo prazo, o interesse em manter-se competitivo e não perder market-share já conquistado.

Vale acrescentar que a equipe responsável pela implantação da TV Digital, reúne-se periodicamente a fim de avaliar as ações que são tomadas com foco no presente, e, para verificar os impactos que elas causarão no momento da implantação da TV Digital, no futuro. Dessa forma, ao se optar pela expansão da rede analógica ou alguma outra atividade que demande investimento, de qualquer espécie e grau de recurso, é sempre avaliado o impacto causado.

Já com o foco no longo prazo, a estratégia da empresa é implantar a TV Digital, a fim de manter-se competitiva. $\mathrm{O}$ vislumbre sobre o impacto em receita advindo pela mudança tecnológica ainda não é muito grande. De acordo com a empresa, tal mudança a princípio não gerará grande incremento nas receitas. Esse é um dos motivos pelo qual houve o atraso consciente da sua implantação, visto que há a necessidade de um grande investimento, principalmente, no que tange à infraestrutura da rede.

Apesar da pouca expectativa de acréscimo na receita a partir da TVDI, observa-se que a organização está atenta às possibilidade de ganhos diante da interatividade que a nova plataforma oferecerá. Atualmente, a rede analógica da emissora já dispõe de um sistema de interatividade que permite a comercialização do seu produto, com redes de operação de telefonia, voz e SMS, por exemplo.

Uma característica válida de ser entendida como um fator relevante e facilitador para a implantação da TVDI pelo SBT/SC é o engajamento da alta direção com o projeto da mudança tecnológica. Além disso, a empresa conta com um corpo técnico diverso e a organização possui uma equipe técnica interdisciplinar composta de profissionais da área de engenharia de telecomunicações e elétrica, ciências da computação, publicidade e informática. Sendo que alguns profissionais possuem mestrado em administração, engenharia e gestão do conhecimento, além de especialização em gestão empresarial e gestão de pessoas.

O início dos trabalhos desta equipe data de março de 2008. A partir daí começou-se a delimitar os temas a serem tratados. Tais como questões legais que envolvam o Ministério das Telecomunicações ou a ANATEL, escolha dos equipamentos e sistemas, além da delineação das macroatividades. Destaca-se que a Televisão Lages Ltda. foi uma das primeiras no Brasil a receber a licença em caráter científico-experimental para a implantação da TV Digital, essa caracterização de outorga deu-se em função da emissora estar localizada no interior e não na capital do Estado, hoje, já houve a solicitação da outorga oficial.

Salienta-se que não houve apoio técnico especializado externo, como a contratação de consultoria. No início dos trabalhos, a empresa entendeu que possuía profissionais técnicos capacitados e que poderiam desenvolver o trabalho e, consequentemente, o conhecimento necessário para tal empreendimento.

A frequência de encontro desta equipe é praticamente diária havendo um bom entrosamento entre os envolvidos e uma constante discussão acerca das atitudes a serem tomadas. Entretanto, observa-se que não há um planejamento formal com controle e avaliação de marcos no projeto. Em contrapartida, um ponto positivo observado é o de que constantemente divulga-se à organização o que está em desenvolvimento, as ações concretizadas e as perspectivas acerca da TV Digital.

De forma geral, observa-se que por mais que a concretização da transição do modelo analógico para o digital possa estar um pouco distante para se efetivar, os impactos que ela tem causado na organização já são visíveis. Na verdade, o que influenciou o modo de realizar o trabalho em algumas áreas afetou a estrutura organizacional da empresa e demandou a contratação de alguns profissionais, principalmente, na área de engenharia.

\subsection{A Produção Baseada em Conhecimento no SBT/SC}

É válido destacar o empenho da organização, que desde 2008, vem somando esforços para modernizar os processos de trabalho a fim de preparar-se para 
o advento da TV Digital. Dentre outros fatores, tais mudanças fornecem subsídios para um novo posicionamento competitivo da organização, visto que por meio dessas melhorias e da atualização tecnológica, ela disponibilizará produtos e serviços no mercado, compatíveis com o avanço da TV Digital.

A estrutura organizacional do SBT/SC era disposta de forma tradicional, havendo uma usual departamentalização conforme as atividades desempenhadas, com diretores específicos para cada uma das unidades regionais. Contudo, já como reflexo da influência da TV Digital, houve uma remodelagem na estrutura da empresa, configurada agora como matricial, tendo em vista sua divisão em torno de duas áreas mercado $e$ produto.

Tal mudança estrutural propiciou interdisciplinaridade, no que tange à divisão em mercado (mídia convencional) e produto (interatividade). Além disso, essa mudança proporcionou uma modificação de conceitos, conta-se hoje com pessoas de desenvolvimento de software, especialistas na área de programação e de interatividade, tendo principalmente o foco no futuro.

Há ainda outro fator que deve ser ressaltado, o fato de não haver na estrutura um departamento que responda pelas atividades de Recursos Humanos da empresa. A função quanto à preparação de folha de pagamento e das demais rotinas de pessoal estão alocadas para a área de Departamento de Pessoal, contudo a gestão de pessoas é transferida para cada gestor da organização.

Um destaque deve ser dado à automatização da captação da informação para o jornalismo. Anteriormente, o processo de produção de notícias, que envolve desde o momento da captação até a recepção da audiência, era feito de forma manual, dependia de um sincronismo de diversas atividades e pessoal, como também estava suscetível a eventuais erros operacionais que comprometiam a qualidade dos resultados esperados.

A partir da automação, houve uma melhoria significativa no fluxo do trabalho, bem como no desempenho das atividades. Os softwares adotados foram fornecidos por uma empresa de Florianópolis. Enquanto um dos programas contribui para a criação, edição, exibição e gerenciamento de imagens do telejornal, o outro possui característica para o fluxo de matérias pela internet, dessa forma, elas podem ser produzidas em qualquer unidade do SBT/SC, e, então, enviadas para a central de jornalismo pela internet, $\mathrm{O}$ que agilizou o fluxo de dados, visto que antes eram feitos por despacho via transporte rodoviário em fitas.

Nota-se que a melhoria no processo, advém não apenas do apoio tecnológico, seja ele dos softwares ou hardwares implantados, mas também pelo preparo e pelo conhecimento dos profissionais envolvidos para a atualização tecnológica. A empresa que forneceu o software e os servidores forneceu treinamento aos principais envolvidos que multiplicaram o conhecimento para os demais envolvidos nas atividades.

Observa-se uma quebra de paradigma, ao superar um processo que era essencialmente manual e que dependia de um grande número de recursos envolvidos, para um novo modelo condizente com as tecnologias disponíveis e que dispõe de profissionais preparados para o uso. O que trouxe ganho na agilidade do desempenho das tarefas, impulsionou o trânsito das informações e também promoveu economia ao não se dispensar tantos recursos envolvidos no processo e redução de tempo.

\subsection{A Gestão do Conhecimento no SBT/SC}

Para a Televisão Lages Ltda. já há uma consciência da administração geral acerca do uso do conhecimento como um recurso. Contudo, não há uma integração em todos os níveis da administração para que esse bem seja gerenciado na sua totalidade na organização.

Observa-se que os gestores valorizam o conhecimento como um recurso, ao estimular o compartilhamento de informações e um trabalho colaborativo, como também ao apoiar ideias práticas que possam ser implementadas. Entretanto, não é possível evidenciar uma abordagem integrada quando se trata de transformar os problemas da empresa em problemas de conhecimento e, dessa forma, verificar os efeitos que as decisões tomadas repercutem sobre os ativos intangíveis da empresa. Além disso, foi possível observar que a empresa trata os problemas caso a caso, e, quando demandadas melhorias em infraestrutura, essa atitude parte de solicitação do gestor de cada departamento para a área de TI que provê a solução adequada, sem muita discussão sobre o assunto. 
Outro ponto que convém evidenciar, quanto à gestão do conhecimento, é o enfoque disposto ao departamento de tecnologia da informação e novas tecnologias, que é responsável pela infraestrutura de TI, de softwares e de equipamentos e soluções referentes à TV Digital. Apesar do alto nível de estruturação, por meio dos softwares utilizados, e, da atualização tecnológica da organização, tal atenção não representa necessariamente uma integração com a gestão do conhecimento, observa-se certa atenção a fim de estruturar e de manter as informações. Outras áreas pertinentes à gestão do conhecimento, como $T \& D e$ $\mathrm{P} \& \mathrm{D}$, apresentam-se como ilhas na empresa, havendo investimento e estímulo tanto para o desenvolvimento quanto para a produção de pesquisas, porém ainda sem uma sistematização. Ressalta-se, novamente, que não há uma área de recursos humanos, já que a gestão e a verificação da necessidade de treinamento é realizada pelos próprios gestores de cada unidade.

Tendo em vista o exposto, verifica-se que a não integração das ações, todavia, é resultado da ausência de coordenação e de alinhamento entre as áreas envolvidas. Dessa forma, ainda que haja iniciativas para o gerenciamento do conhecimento, se os colaboradores não tiverem as habilidades necessárias para utilizar as informações disponíveis ou para, por meio delas, gerar novas descobertas que influenciem significativamente suas rotinas de trabalho, o valor gerado a partir do conhecimento deles será limitado, podendo ser entendido como pequeno ou nulo.

Entretanto, não se deve desmerecer os esforços que a organização já tem empreendido. Principalmente no que tange à cultura organizacional que aparenta ser de estímulo e troca de experiências, com uma boa acessibilidade dos colaboradores aos seus gestores para a colocação de ideias e sugestões, o que em parte é apoiado pela estrutura organizacional, mas também reforçado pelo estímulo oferecido pelos gestores.

Dessa forma, verifica-se que o SBT/SC possui recursos tangíveis, como equipamentos, softwares, estações de trabalho, estrutura, capital, entre outros, e, também, possui ativos intangíveis, sejam eles provenientes do conhecimento de seus colaboradores, do relacionamento interno que existe entre eles, $e$, entre eles e o mercado, além da referência da marca. Contudo, não há uma abordagem sistematizada que oriente a aplicação dos recursos em busca de uma gestão eficaz do conhecimento.

\section{As metas de conhecimento para a organiza-} ção - é possível verificar que para a Televisão Lages Ltda., ainda, não há uma explicitação quanto às metas de conhecimento desejáveis pela organização. Há um empenho consciente, porém não formal ou sistemático, a fim de socializar o conhecimento e difundi-lo como cultura predominante.

Pensando em políticas internas, visão de conhecimento e declaração de missão, também nota-se a ausência desses itens na organização, assim como uma identificação de áreas críticas de conhecimento. De forma ampla, pode-se dizer que a organização está consciente das melhorias que necessita realizar, no entanto, não houve investimentos em tais mudanças.

Conforme a opinião dos gestores, a cultura da empresa é saudável. Há a busca por um ambiente colaborativo por parte dos gestores para com a sua equipe. Existe abertura para a colocação de dúvidas, de melhorias e de busca de soluções para problemas experimentados pela equipe junto aos seus gestores.

Já em se tratando de competências essenciais da organização, verifica-se que não há um programa formal institucionalizado que auxilie a TV Lages Ltda. a manter seu crescimento e lucratividade no ambiente onde está inserida, e que se preocupe com a necessidade da empresa em considerar-se um portfólio de competências. Nota-se que há investimentos para aprimorar as habilidades técnicas dos colaboradores, por meio de incentivos educacionais ou de patrocínio de cursos, entretanto, sem uma ligação que una o desenvolvimento sistêmico às competências essenciais da organização.

A empresa opta por não utilizar métodos de computer based training porque possui uma abordagem similar a um apadrinhamento. Quando um novo colaborador ingressa, é realizado um treinamento com ele num período de uma a duas semanas, ministrado por um profissional da área, para que o novo colaborador se atualize com as ferramentas que utilizará. Essa abordagem é válida porque estimula uma transmissão do sistema de valores por meio da externalização.

A Televisão Lages Ltda. busca fomentar práticas de cooperação entre as pessoas na organização, através do incentivo impulsionado pelos gestores para que tal 
prática seja adotada. Nesse sentido, a Televisão Lages Ltda. iniciou uma série de cursos para seus gestores na área de eneagrama, pois, de acordo com a empresa, é importante que eles conheçam tanto as pessoas com quem trabalham como também os seus clientes. Essa abordagem do eneagrama visa fornecer subsídios para as organizações melhorarem seu clima organizacional, bem como o relacionamento com os clientes.

Observa-se que em se tratando de metas normativas, a empresa possui um comportamento empírico de fomentar a cultura organizacional da disseminação do conhecimento e da realização do trabalho colaborativo, entretanto, sem uma definição de missão e visão de conhecimento.

Quanto às metas estratégicas que definem o conhecimento vital da organização e determinam as habilidades que serão necessárias no futuro, nota-se que os gestores estão preparados para o desenvolvimento e o estímulo dos colaboradores com relação às habilidades técnicas requeridas para o desempenho das funções atuais, e, considerando, posteriormente, a implantação da TV Digital. Contudo, eles o fazem sem uma conexão do desenvolvimento de competências individuais tendo em vista as competências essenciais da organização.

Finalmente, em relação às metas operacionais, que visam à implementação da gestão do conhecimento $e$ que traduzem as metas normativas $e$ as estratégicas em objetivos concretos, a empresa adota uma infraestrutura que dá suporte às atividades $e$ permite a disseminação do conhecimento, com softwares adequados e uma equipe de TI atualizada com as necessidades da empresa. Porém, em função da ausência do estabelecimento de metas normativas $e$ estratégicas, não se pode concluir que essas iniciativas são as metas operacionais da empresa, mas sim uma orientação da empresa a uma inicial abordagem para a gestão do conhecimento.

\section{Processos Essencials de Gestão do Conhecimento}

A identificação do conhecimento existente na organização - no que tange ao ambiente de conhecimento da empresa, é importante ressaltar, uma vez mais, a peculiaridade da organização em não possuir uma área formal estabelecida para a Gestão de Recursos Humanos. Dessa forma, muitas das ações que estão ligadas ao mapeamento do conhecimento individual não estão formalizadas. Ilustrativamente, pode-se dizer que quando a organização contrata um colaborador, o responsável pela seleção desse novo integrante da equipe realiza o recrutamento de maneira empírica. Os preceitos para a avaliação do cargo não estão evidentes, ou seja, não há um desenho do cargo com os requisitos, conhecimento, habilidade e atitudes, exigidos para as atividades. Dessa forma, perde-se a oportunidade de iniciar a identificação do conhecimento a partir da admissão de um colaborador.

Já, tendo em vista o ambiente externo, a organização também lança um olhar atento para essa área. Foi realizado um levantamento no âmbito externo da organização a fim de verificar um indicador de prontidão do capital organizacional para essas empresas baseadas em conhecimento envolvidas no processo da TVDI. O objetivo deste estudo foi verificar um índice de medida que pudesse mensurar a prontidão estratégica dessas empresas.

A organização, a partir dos resultados daquele estudo, busca, posteriormente, realizar uma pesquisa que poderá utilizar o índice proposto, como forma de verificar a prontidão de seus stakeholders. Tais resultados propiciarão uma base de informações que poderá subsidiar as prováveis tomadas de decisão da organização quanto às suas ações com foco na TVDI.

Denota-se que não há, atualmente, uso de instrumentos que possam evidenciar o conhecimento existente na organização, ou mesmo a localização de fontes de conhecimento. Há, por parte da organização, um conhecimento tácito acerca do que está disponível e onde estaria acessível, sendo comum a prática de conversação e de discussão acerca de algum eventual problema ou necessidade de informação. Entretanto, nenhum instrumento formal foi evidenciado.

Aquisição de conhecimento - a Televisão Lages Ltda. utiliza-se da informação como matéria-prima. Seja para a produção dos telejornais, para o desenvolvimento de produtos interativos que se comuniquem ora com o sinal analógico, ora com o futuro advento da TVDI, ou ainda como insumo para suas atividades básicas, sejam elas referentes ao faturamento e ao marketing institucional de produtos ou dentre outras finalidades. 
Observa-se que a organização tem se disposto a ser objeto de estudo de diversos trabalhos acadêmicos para que dessa forma possa contar com conhecimento acadêmico externo e usufruir de uma leitura independente que contribua com os esforços de gestão.

As pessoas na Televisão Lages Ltda. são vistas por seus gerentes como fundamentais para a geração de receita. Com relação aos gerentes, a base de poder deles depende de um nível relativo de conhecimento técnico e de uma composição de relacionamento interpessoal, a fim de fundamentar um apoio aos colegas para a execução de tarefas.

A informação na empresa está mais para ferramenta como recurso de comunicação do que para instrumento de controle. Já ao se ter em vista o ramo de atuação da empresa, a produção é caracterizada por uma conversão de conhecimento de seus colaboradores em estruturas intangíveis, e o fluxo das informações produzidas dá-se por meio de redes colegiadas, principalmente, em função da estrutura organizacional da empresa, que é matricial. Ainda em se tratando de produção, pode-se verificar que o fluxo de produção não é regido por máquinas, pelo contrário, é regido pelas ideias.

Outro ponto que merece destaque é o relacionamento com o cliente, que se dá por forma interativa pelas redes pessoais, havendo até mesmo atitudes inovadoras da empresa de já constituir um blog para estar presente nas redes sociais.

A colaboração das pessoas na organização para o desempenho de suas atividades dá-se por meio presencial com a discussão de temas em reuniões ou por meio de acesso a arquivos e documentos.

\section{$O$ treinamento e desenvolvimento do co-} nhecimento - é praticado sem o apoio sistemático da empresa. Ocorre devido ao planejamento dos gestores de cada área. Sendo que, então, as tradicionais etapas de diagnóstico, planejamento, execução e avaliação são desempenhadas autonomamente por cada área da empresa, não necessariamente iniciando com o diagnóstico do gestor para a necessidade do treinamento. Tal início pode também partir de um colaborador que apresenta ao seu gestor o interesse em participar de algum curso ou evento a fim de aprimorar determinada área de conhecimento.

Sendo assim, verifica-se que não há um planejamento acerca das diretrizes e dos objetivos do T\&D, havendo um alinhamento empírico deles com os macro-objetivos da organização. Apesar disso, a empresa tem financiado diversos cursos de curta a longa duração, como por exemplo, o auxílio-educação para cursos de graduação ou até mesmo de pós-graduação.

A partir da colocação anterior, outro ponto importante de ser salientado é o de que não há um plano de cargos e salários instituído com o desenho prestabelecido de cada função. Assim como ainda não há a determinação das premissas esperadas para as competências individuais, de forma que a avaliação do treinamento fica prejudicada por não contar com parâmetros que subsidiem sua análise e não permitam, dessa forma, o uso de indicadores. A mensuração e a verificação do retorno se dão por meio informal por meio da constatação do gestor da aplicabilidade do retorno proporcionado pelo treinamento.

Observa-se, assim, que a questão treinamento $e$ desenvolvimento não é abordada sob uma perspectiva sistêmica pela organização. Apesar de haver iniciativa da empresa em patrocinar cursos de longa duração com foco no desenvolvimento, e, de curta duração com foco no treinamento, uma abordagem sistêmica beneficiaria a organização a adquirir vantagem competitiva através do uso da gestão do conhecimento.

Partilha e distribuição do conhecimento para o presidente da organização, o conhecimento de seus colaboradores ainda está eminentemente tácito e compartimentado a eles. Entretanto, conforme evidenciado por ele, ainda não há um programa formal para estimular a distribuição do conhecimento entre os colaboradores. Embora não haja uma iniciativa em curso, a organização reconhece a necessidade e tem o interesse em desenvolver a distribuição do conhecimento, de forma a atingir a espiral do conhecimento. Ou seja, partindo da socialização, para a externalização, a combinação para subsidiar o conhecimento sistêmico, com consequente internalização oferecendo informações operacionais e iniciando o ciclo novamente.

Observa-se, dessa forma, num macrocontexto, uma preocupação da organização em dividir as informações acerca dos principais eventos que influenciem a gestão. Já em relação ao microambiente, a empresa adota um layout que favorece a comunicação entre os colaboradores e, dessa forma, estabelece a troca de conhecimentos. 
De uma forma geral, quando algum colaborador participa de um congresso, feira, evento ou treinamento, ele é convidado a compartilhar seu conhecimento acerca do conteúdo que foi verificado no treinamento. Isso acontece numa espécie de multiplicação do conhecimento, por meio da qual ele divide sua experiência com seus colegas mais próximos e que tenham formações similares. Também é disponibilizado à organização o material que foi obtido nos treinamentos como apresentações e apostilas, distribuídos por e-mail aos colaboradores com atividades pertinentes ao objeto do estudo.

Verifica-se, então, que o compartilhamento dá-se em sua maioria por medidas informais, não sendo decorrente de algum programa instituído pela organização. Os gestores estimulam a distribuição do conhecimento, o que é feito geralmente através de reuniões e por meio de arquivos e documentos. Além de contar com a abordagem do apadrinhamento no treinamento de novos colaboradores.

Utilização do conhecimento - ao pensar em os diversos usos para o qual o conhecimento pode servir, verifica-se que sua utilização é relevante desde os pequenos processos operacionais até os propósitos estratégicos. Dessa forma, é útil para a organização buscar o seu uso em todas as esferas possíveis. O cenário visualizado no SBT/SC, quanto ao uso do conhecimento, apresenta-se um pouco fragmentado. Por vezes, o conhecimento e seu uso intrínseco se dão em operações rotineiras da empresa, mas também se vê na adoção de um aspecto estratégico, ao preparar-se para a implantação da TV Digital e, dessa forma, manter-se competitivo no mercado.

Entretanto, entre essas duas abordagens, há também o uso do conhecimento com uma finalidade tática, que estaria a encargo dos gestores. Esses gestores possuem em seu benefício o uso do programa desenvolvido pelo gestor de TI e novas tecnologias, os Relatórios Gerenciais via Web, que está integrado ao ERP da empresa e possibilita o acesso e a filtragem das informações desejadas, a fim de se obter um relatório ou gráfico com fins específicos. Tal programa foi criado para atender às expectativas quanto ao uso do conhecimento e à extração de relatórios customizados.

Há uma conjugação do uso do conhecimento existente na empresa, onde cada área o utiliza conforme suas necessidades. Destaca-se, porém, que por ele ser um elemento construtivo é necessário agregar valor a ele por meio da aquisição, do desenvolvimento e do acúmulo do conhecimento, dessa forma, esse conhecimento poderá, além de ser utilizado, ser reutilizado. Para tanto conta-se com uma adequada estruturação do ambiente de trabalho de forma a contemplar as necessidades individuais e da equipe, para que o uso do conhecimento seja potencializado.

Retenção do conhecimento - em se tratando de reter o conhecimento, como uma abordagem de reter o capital intelectual presente na organização, podese dizer que as medidas empregadas pela Televisão Lages Ltda. são atitudes informais da parte dos seus gestores ao trabalharem com sua equipe. Não há uma política institucionalizada de recursos humanos que estimule a permanência do colaborador com opções de plano de desenvolvimento ou de incentivos financeiros.

Ao pensar na evasão do conhecimento de um colaborador de destaque, que seja habilidoso em suas funções, atualmente, não há uma sistematização para que se explicite o conhecimento dele. Diante desse quadro, observa-se que a questão de armazenagem carece, todavia, de um alinhamento a fim de reter o conhecimento existente na organização.

Avaliação do conhecimento - é um item essencial para mensurar o desempenho da gestão do conhecimento organizacional. Por meio dessa avaliação é possível verificar pontos que necessitam ajustes e aqueles que estão demonstrando resultados satisfatórios. Ela vai ao encontro dos objetivos já formulados para a gestão do conhecimento organizacional. Nesse sentido, verifica-se que por mais que haja intento $e$ iniciativa da organização em promover o uso e a distribuição do conhecimento, ou ainda que ela já tenha produtos inovadores em função do conhecimento em ação de seus profissionais, e, utilize tecnologias de convergência tecnológica, não é possível evidenciar um sistema de gestão implantado com metas e objetivos estabelecidos. O que dificulta a mensuração para a avaliação do sistema.

As mudanças ocorridas na Televisão Lages Ltda., ocasionadas pela implantação da TVDI, incentivaram abordagens de valorização do conhecimento organizacional, contudo, a empresa ainda atua e deve continuar operando até meados de 2016 nos moldes da tecnologia analógica. Entretanto, ciente do impacto que a mudança causará no mercado e em seus 
usuários, o SBT/SC já inicia passos rumo à gestão do conhecimento, porém, não de forma sistemática, o que inviabiliza a mensuração desse elemento construtivo no presente momento.

\section{Considerações Finais}

O advento da TV Digital impulsionará diversas mudanças no âmbito das telecomunicações, as quais podem ser entendidas como novas oportunidades de serviços e produtos de alto valor agregado. Num cenário com considerável velocidade no fluxo das informações, as mudanças são evidentes e o conhecimento transforma-se em poder. Assim, as empresas precisam obter uma qualidade na reação que apresentam em função das pressões competitivas, como também adaptar-se internamente para competir num cenário de constantes mudanças. Destarte, para que a empresa possua uma base que suporte a sua vantagem competitiva e para que seus gestores desenvolvam os ativos de sua organização, a gestão do conhecimento é uma solução.

Sendo assim, buscou-se neste trabalho verificar a condução da implantação da TV Digital, pela Televisão Lages Ltda., sob a perspectiva da gestão do conhecimento. Logo, pode-se verificar que a organização tinha um planejamento para que no ano de 2009 houvesse já o simulcast, entretanto, em razão de um reposicionamento estratégico, tal intento foi postergado e sujeito a uma nova análise. A Televisão Lages Ltda. optou por neste período realizar uma melhoria e uma adequação à rede analógica já existente, para que na ocasião do pareamento que ocorrerá com a TV Digital seja possível usufruir de infraestrutura adequada.

Ainda que não seja iminente a implantação do sinal digital, a emissora possui uma equipe técnica interdisciplinar responsável por analisar todos os quesitos pertinentes à mudança tecnológica. Essa equipe analisa as ações que são tomadas com foco no analógico $e$ na TV Digital para buscar sempre o melhor uso dos recursos da organização.

Verifica-se que a estrutura organizacional do SBT/ SC foi influenciada pela implementação da TV Digital, antes disposta de forma tradicional, remodelou-se e pode ser caracterizada como matricial. Tendo agora uma organização em torno de duas áreas: mercado e produto.

Ao partir para o levantamento das metas de conhecimento para a Televisão Lages Ltda., constatou-se que para as metas normativas há um comportamento empírico de fomentar a disseminação do conhecimento $e$ a realização de um trabalho colaborativo, entretanto, sem uma definição de missão e visão de conhecimento. Quanto às metas estratégicas que definem o conhecimento vital da organização e determinam as habilidades que serão necessárias no futuro, nota-se, todavia que não há uma conexão do desenvolvimento de competências individuais tendo em vista as competências essenciais da organização, embora, os gestores busquem o desenvolvimento e o estímulo dos colaboradores quanto às habilidades técnicas requeridas para as funções exercidas.

Finalmente, em relação às metas operacionais que buscam a implementação da gestão do conhecimento e transformam as metas normativas $e$ estratégicas em objetivos concretos, observou-se que a empresa possui uma infraestrutura adequada para a disseminação do conhecimento, já que possui softwares e uma equipe de TI atualizados com as necessidades da empresa, porém, perante a ausência de metas normativas e de estratégicas, não se pode concluir que tais iniciativas sejam as metas operacionais da empresa, mas sim uma orientação a uma inicial abordagem para a gestão do conhecimento.

Tendo em vista os processos essenciais de gestão do conhecimento, verifica-se que, com relação à identificação do conhecimento, esas relação acontece de forma tácita, através do conhecimento do gestor acerca do perfil de colaboradores que ele tem em sua equipe, não há um mapeamento formal que explicite o conhecimento existente na empresa. Já em se tratando de ambiente externo, a empresa tem buscado realizar parcerias com universidades, acadêmicos ou professores para a realização de estudos.

Quanto à aquisição do conhecimento verificou-se que a Televisão Lages Ltda. é sensível à importância da valorização do conhecimento, e, portanto, tem estimulado seus profissionais a buscá-lo, seja em cursos de curta duração, ou cursos de graduação e até mesmo pós-graduação. Não obstante, a organização tem sido objeto de estudo de alguns trabalhos acadêmicos, o 
que promove à organização uma aquisição de conhecimento com uma visão imparcial.

Referente ao desenvolvimento do conhecimento, a organização não possui uma abordagem sistematizada para tratar desse processo. Há o envolvimento dos gestores com sua equipe para a verificação da necessidade de um curso para treinamento ou desenvolvimento, bem como a solicitação por parte dos colaboradores ao seu superior hierárquico para a participação em algum programa tendo em vista o aperfeiçoamento do conhecimento. Contudo, não há um desenho de cargo ou abordagem que privilegie a contemplação das competências individuais. $\mathrm{O}$ investimento que é feito busca suprir uma necessidade pontual, não havendo a conexão com a intenção de desenvolvimento de conhecimento, habilidades e atitudes a fim de se atingir os objetivos organizacionais.

Concernente à partilha e à distribuição, verifica-se que há um ambiente organizacional colaborativo e que estimula a interação entre as pessoas. Essa verificação está pautada nos resultados coletados no questionário aplicado à organização. Embora haja um interesse da organização de fomentar a prática da disseminação do conhecimento, utilizando conceitos da espiral do conhecimento proposto por Nonaka e Takeuchi (1997), não foi evidenciado o uso, atualmente, de algum programa organizacional que estimulasse tal prática.

Já em relação a esse uso, verifica-se que o cenário visualizado no SBT/SC apresenta-se um pouco fragmentado, havendo o conhecimento e uso intrínseco dele para as operações rotineiras da empresa, como também na perspectiva estratégica, ao fundamentarse para a implantação da TV Digital e, dessa forma, manter-se competitivo no mercado. Observa-se também o uso do conhecimento com uma finalidade tática, que estaria a encargo dos gestores, os quais encontram nos relatórios gerenciais, via Web, um subsídio para a sua tomada de decisão.

Em se tratando de reter o conhecimento, constata-se que as medidas empregadas pela Televisão Lages Ltda. são atitudes informais dos seus gestores no trabalho com suas equipes. Não há uma política de $\mathrm{RH}$ institucionalizada que estimule a permanência do colaborador com opções de plano de desenvolvimento ou incentivos financeiros, ou ainda, uma prática que busque o arquivamento do conhecimento em documentos, planilhas ou processos institucionalizados.
Por fim, com efeito de avaliar o conhecimento, verifica-se que a Televisão Lages Ltda. possui iniciativas em promover o uso e a distribuição do conhecimento, além disso, a TV Lages Ltda. Obtém, como produto do conhecimento, mudanças em processos que evidenciam não apenas uma automatização, mas a agregação de conhecimento, como na automação do telejornalismo. Contudo, não é possível evidenciar um sistema de gestão implantado com metas e objetivos de conhecimento estabelecidos, o que inviabiliza a avaliação do sistema.

Portanto, como sugestão de melhoria, para a abordagem até o momento adotada, sugere-se à Televisão Lages Ltda. que ela adote uma visão integrada acerca do seu capital intangível, para, dessa forma, assegurar uma base de conhecimento que seja bem utilizada e de caráter contínuo. Isso pode ser facilitado por meio de uma sensibilização em todos os níveis da administração quanto à importância do conhecimento como um recurso. Num contexto de gestão, faz-se necessária a discussão de enfoques como: o papel a ser desempenhado pela alta gerência; quais seriam as novas práticas de trabalho na organização; os processos específicos a serem criados, com a intenção de facilitar as práticas e as políticas de gestão de recursos humanos; as novas tecnologias de informação, bem como a comunicação e o relacionamento com o ambiente interno e externo.

Nesse sentido, outra ação demandada seria o estabelecimento de políticas e programas de recursos humanos que subsidiem a gestão do conhecimento por meio de práticas usuais da gestão de pessoas. Tal como um sistema de educação corporativa pautado nas competências individuais com o fim de complementar as competências organizacionais da empresa. Essa proposta é justificada visto que o conhecimento tem se tornado um dos principais componentes daquilo que é produzido, comprado ou vendido. Logo, a gestão do conhecimento busca localizar e estimular o capital intelectual e armazená-lo, vendê-lo e compartilhá-lo.

Tais sugestões são realizadas a fim de proporcionar vantagem competitiva para a Televisão Lages Ltda. em seu âmbito de atuação. Isso porque, com uma abordagem integrada perante o conhecimento, há um uso consciente de novas habilidades dos colaboradores, há criação de novos produtos, surgimento de ideias melhores e processos mais eficientes, até mesmo 
mais econômicos. Não obstante, pode-se proporcionar à organização um posicionamento único no mercado, mediante a possibilidade de inovações em seu setor de atuação. Para se atingir tal cenário, é necessário um esforço organizacional direcionado para o conhecimento, com uma gestão administrativa que visa produzir capacidades que ainda não estão presentes na organização ou até mesmo que não existem fora dela.

\section{REFERÊNCIAS}

ANGELONI, Maria Terezinha. Organizações do conhecimento: infra-estrutura, pessoas e tecnologias. São Paulo: Saraiva, 2002.

\section{DAVENPORT, Thomas H. Pense fora do quadrado:}

descubra e invista em seus talentos para maximizar resultados da sua empresa. Rio de Janeiro: Elsevier, 2006.

DRUCKER, Peter F. Desafios gerenciais para o século XXI. Tradução de Nivaldo Montingelli Júnior. São Paulo: Pioneira, 1999.

. Além da Revolução da Informação. In: JÚLIO, Carlos Alberto; NETO, José Salibi. (Org.) E-business e tecnologia: autores e conceitos imprescindíveis. São Paulo: Publifolha, 2001. (Coletânea HSM Management)

KELLY, Kevin. A Economia interconectada. In: JÚLIO, Carlos Alberto; NETO, José Salibi (Org.) E-business e tecnologia: autores e conceitos imprescindíveis. São Paulo: Publifolha, 2001. (Coletânea HSM Management)

LOBATO, David Menezes et al. Estratégia de

empresas. 7. ed. Rio de Janeiro: FGV, 2006.

MACHADO, Arlindo. A Televisão levada a sério. 2. ed. São Paulo: Editora SENAC, 2001.

MONTEZ; Carlos. BECKER; Valdecir. TV digital

interativa: conceitos, desafios e perspectivas para o Brasil. 2. ed. Florianópolis: EdUFSC, 2005.

NONAKA, Ikujiro; TAKEUCHI, Hirotaka. Criação de conhecimento na empresa. Rio de Janeiro: Campus, 1997.
OLIVEIRA NETTO, Alvim Antônio de; MELO, Carina.

Metodologia da pesquisa científica: guia prático para a apresentação de trabalhos acadêmicos. 2. ed. rev. e atual. Florianópolis: Visual Books, 2006.

PROBST, Gilbert. RAUB; Steffen. ROMHARDT, Kai.

Gestão do conhecimento: os elementos construtivos do sucesso. Tradução: Maria Adelaide Carpigiani. Porto Alegre: Bookman, 2002.

ROCHA-PINTO, Sandra Regina da et al. Dimensões funcionais da gestão de pessoas. Rio de Janeiro: FGV, 2007.

SILVA, Antonio Carlos Ribeiro da. Metodologia da pesquisa aplicada à contabilidade: orientações de estudos, projetos, artigos, relatórios, monografias, dissertações, teses. São Paulo: Atlas, 2003.

SMITH, Anthony F.; KELLY, Tim. O capital humano na economia digital. In: HESSELBEIN, Frances; GOLDSMITH, Marshall; BECKHARD, Richard; THE PETER F. Drucker Foundation. A Organização do futuro: como preparar hoje as empresas de amanhã. 2. ed. São Paulo: Futura, 1997.

STEWART, Thomas A. Capital intelectual. 5. ed. Rio de Janeiro: Campus, 1998.

SVEIBY, Karl Erik. A Nova riqueza das organizações. Rio de Janeiro: Campus, 1998.

\section{TERRA, José Cláudio Cyrineu. Gestão do}

conhecimento: o grande desafio empresarial: uma abordagem baseada no aprendizado e na criatividade. São Paulo, Negócio Editora, 2000.

ZANELLA, Liane Carly Hermes. Universidade Federal de Santa Catarina, Secretaria de Educação a Distância. Metodologia da pesquisa. Florianópolis, SEAD/UFSC, 2006. 